\title{
AS NOTÍCIAS REGIONAIS NO TELEJORNAL DA RTP: QUE SERVIÇO PÚBLICO? *
}

\author{
FELISBELA LOPES **
}

\section{RESUMO:}

Considerando o serviço público de televisão algo de primordial em qualquer panorama audiovisual europeu, pretendemos, neste artigo, analisar quais os assuntos regionais que o canal público generalista português (RTP1) mediatizou no seu principal programa de informação: o Telejornal. O período de estudo remonta aos anos de 1988 (ano de absoluto monopólio) e de 1992 (ano em que Portugal recebe as emissões da primeira estação privada de televisão, a SIC). Antes de expormos os nossos resultados, faremos uma breve incursão pela génese do serviço público de televisão e pelos princípios e valores que a estruturam.

\section{Introdução}

Tendo um papel integrador fulcral no seio da sociedade, a televisão assume-se como um media, se não omnipotente, pelo menos omnipresente, permitindo às pessoas sair do seu isolamento para partilhar um determinado conhecimento: aquele que é proporcionado por determinada emissão. Todavia, há quem defenda que a TV não constitui o meio de informação ideal. Pierre Bourdieu é uma das vozes críticas do saber proporcionado pelo audiovisual, assegurando que «não se pode dizer grande coisa na tele-

\footnotetext{
* O texto deste artigo resulta do livro O Telejornal e o Serviço Público (Minerva, Coimbra, 1999) publicado pela autora.

** Assistente do Departamento de Ciências da Comunicação da Universidade do Minho. E-mail: felisbela@ics.uminho.pt
} 
visão" (1997: 3). Giovanni Sartori (1998) diz mesmo que a televisão é culturalmente regressiva, transformando o «homo sapiens» (um ser capaz de reflectir tudo o que diz e que se movimenta num «mundus intelligibilis») num «homo videns» e, consequentemente, num "homo ludens" (um ser vocacionado para receber passivamente mensagens visuais e que apenas vê o «mundus sensibilis»). Não partilhamos pressupostos tão radicais, concedendo ao pequeno ecrã uma certa capacidade para transmitir informação. Situados aqui há, então, que equacionar os conteúdos televisivos a partir da natureza do canal que os transmite.

Numa altura em que se tentam criar pontes que aproximem o actor solitário da sociedade individualista de massas, a televisão de serviço público adquire uma importância acrescida. Daí ser imprescindível que a paleta de programas reflicta a heterogeneidade social e cultural de determinada comunidade. A estação pública de televisão deve ser uma janela aberta contra a exclusão, contribuindo para a integração social e cultural, a fim de se garantir a coesão nacional, cada vez mais debilitada numa sociedade progressivamente mais planetária. Favorecendo os novos media a segmentação dos telespectadores, a TV pública deve procurar, através dos seus programas, federar públicos diversificados que, apesar de arrastarem consigo inevitáveis especificidades, poderão, à mesma hora, reunir-se em frente do pequeno ecrã para partilharem a mesma emissão televisiva.

Neste artigo iremos analisar o tipo de acontecimentos que a estação portuguesa de serviço público, através do seu programa informativo de maior audiência - o Telejornal da RTP1 - mediatizou fora da capital do país. O período da nossa amostra remonta aos anos de 1988 (altura em que a TV pública operava em regime de monopólio) e de 1992 (ano em que se conhecem os vencedores do concurso dos canais privados e em que a primeira estação privada, a SIC, inicia as suas emissões).

\section{O serviço público de TV: génese}

Perspectivar o serviço público de televisão implica procurar as suas raízes no meio que o antecedeu, ou seja, na rádio. Foi ela que formou os profissionais do pequeno ecrã; foi nela que se criou o embrião dos conteúdos audiovisuais que viriam a revolucionar a nossa forma de estar; foi a partir dela que se ensaiaram as descobertas tecnológicas que permitem hoje receber, em cada uma das nossas casas, o som e as imagens daquilo que acontece do outro lado do mundo ou ao fundo da nossa rua. Se o que somos é mais facilmente entendível quanto melhor conhecermos aquilo que fomos no nosso passado, também a lógica de funcionamento da televisão só poderá ser compreendida à luz daquilo que foi o seu principal antepassado: a rádio. 
Circunscrevendo-nos às descobertas tecnológicas aplicáveis à rádio, verificamos que as mais importantes foram feitas em território europeu 1. No entanto, foram os americanos os grandes fomentadores da radiodifusão. Pátria do liberalismo económico, os EUA cederam o espectro hertziano aos privados que montaram à volta dele uma indústria florescente. Na Europa o desenvolvimento foi mais lento e seguiu outro modelo, devido mais a condicionalismos históricos do que propriamente económicos. Nascida praticamente no limiar da I Guerra Mundial, a rádio é rapidamente circunscrita a uma função: servir de instrumento de comunicação militar, tendo um papel decisivo nas operações navais, especialmente na guerra submarina. Os políticos aperceberam-se rapidamente das vantagens daquele meio pelo que, terminados os conflitos, trataram de criar normativos que perpetuassem o poder sobre ele. Este domínio, mais ou menos estreito, do poder político sobre as rádios europeias atrasou significativamente o seu crescimento. Ao contrário daquilo que acontecia nos EUA, na Europa a rádio não dispunha de margens financeiras que lhe permitissem desenvolvimentos audazes quer ao nível tecnológico quer ao nível dos conteúdos, o que viria a condicionar o seu desenvolvimento.

A televisão vai nascer como um apêndice da rádio: herda-lhe os profissionais, aproveita parte dos seus recursos técnicos, adapta os seus conteúdos e adopta o seu modelo de funcionamento. Como aconteceu com a radiodifusão, as primeiras experiências televisivas são ensaiadas na Europa 2. Um acontecimento, porém, faz arrefecer o entusiasmo em torno da televisão: a II Guerra Mundial. O fim dos conflitos marca verdadeiramente o início das emissões audiovisuais, sendo os EUA, menos enfraquecidos pela guerra, a tomar a liderança.

Retomando o modelo de liberdade de empreendimento adoptado na rádio, a televisão americana foi, pelo menos nos seus primórdios, financiada exclusivamente pela publicidade e entregue ao sector privado. Cedo se começaram a notar excessos, fruto da política comercial que tinha como objectivo principal a rentabilização das emissões. A publicidade ocupava tempos de antena substanciais, alargando-se até ao campo político, o que

1 Em 1864, Maxwell, um escocês, apresentou a teoria do conjunto das ondas magnéticas ao lado das ondas luminosas; em 1887, Hertz, um alemão, fez uma descoberta que ficou para sempre ligada ao seu nome, as ondas hertzianas; em 1890, Branly, um francês, construiu o primeiro radiocondutor; e, em 1894, Marconi, um italiano, realizou as primeiras experiências comprovativas da comunicação à distância em código morse através das ondas hertzianas.

2 John Logie Baird cria, em 1925, um televisor para o qual obtém uma licença experimental em 1926; em França, Eugène Belin e Howeck conseguem, em 1926, a recepção de imagens num ecrã catódico; na Alemanha, os Correios patrocinam, em 1928, emissões em 30 linhas. 
ainda hoje é considerado polémico. Os atropelos também se acumulam ao nível da programação. Numa tentativa de controlar esta situação, o Congresso vota, em 1967, o Public Broadcasting Act, que institui uma rede de televisão pública cujo funcionamento ficará dependente do orçamento federal. Em 1969 cria-se a Corporation for Public Broadcasting, encarregue de repartir o subsídio previsto e planificar o PBS (Public Broadcasting Service), que reúne em rede um certo número de estações televisivas. Todavia, essas cadeias de televisão caracterizam-se por uma programação marginal, dirigida principalmente às elites, não conseguindo, ainda hoje, uma força que lhes permita uma forte implantação na paisagem audiovisual americana 3 .

Céptica em relação ao liberalismo nas comunicações, a Europa segue outro modelo, o de serviço público, confiando o controlo da radiotelevisão ao Estado, como, aliás, já acontecia com a rádio. Por detrás desta ligação estão as mutações económicas, sociais e políticas que se seguiram às duas grandes Guerras Mundiais e que obrigaram o Estado de vários países europeus, mais atingidos pelos confrontos, a adoptar um novo papel a fim de contribuir para o fortalecimento das economias e para o estabelecimento dos equilíbrios sociais - missões que a sociedade não conseguia cumprir e que o livre funcionamento do mercado era incapaz de realizar. É, pois, no seio deste Estado Providência que nasce, em terreno europeu, a força dos serviços públicos, expressão da actividade prestacional da Administração com o fim de promover bem-estar aos cidadãos. O poder transforma-se, deste modo, em função de serviço, tornando-se a satisfação das necessidades colectivas um dos principais fins do Estado Providência (Estorninho, 1996: 37). A referência ao serviço público confere-lhe uma legitimidade de intervenção renovada, menos transcendente e, por isso, mais funcional, pois o que aqui importa são as acções em prol do bem comum. A sua autoridade adquire um novo élan.

Esta transformação, que acontece no início do século XX, tem repercussões em vários sectores da sociedade (Amaral, 1989: 335). A televisão foi apenas um dos campos de actuação do poder político, com particular visibilidade na Europa. Giuseppe Richeri (1993/1994: 46-47) aponta como argumentos justificativos do envolvimento do Estado na actividade televisiva, nomeadamente nas formas de financiamento público e nas funções de utilidade pública da televisão, os seguintes factores:

- De ordem técnica. Constituindo nos primórdios da televisão um bem raro, as frequências hertzianas foram alvo de uma regulamen-

3 A evolução da televisão nos Estados Unidos é traçada por Roland Cayrol em Les Médias - presse écrite, radio, télévision, Presses Universitaires de France, 1ère Ed,, 1991, pp. 326-337. 
tação criteriosa por parte do Estado, que, para além de decidir a sua distribuição, fixava as regras para o seu funcionamento, a fim de garantir o interesse colectivo. Pretendia-se que a televisão chegasse a todo o território nacional, oferecendo a cada cidadão as mesmas oportunidades de acesso. Um propósito que ainda hoje continua actual. Neste caso, o serviço público é concebido como urna «grande infra-estrutura técnica».

- De ordem politica. Atribui-se aos operadores públicos uma função fundamental para a democracia: promover a participação dos cidadãos na discussão de assuntos de interesse público, abrindo a antena a diferentes tendências políticas, sociais e culturais. Para além do pluralismo, espera-se deles uma informação objectiva e independente. Para Richeri, a «televisão pública é a grande ágora moderna onde se forma e manifesta a opinião pública».

- De ordem cultural ${ }^{4}$. Exige-se da televisão pública uma resposta eficaz às necessidades informativas, formativas e de entretenimento dos cidadãos, colocando no centro das suas preocupações a promoção da cultura nacional. Neste contexto, o serviço público é, segundo Richeri, "uma grande estrutura educativa».

- De ordem jurídica. Dos canais públicos espera-se um trabalho de interesse geral que garanta um direito estabelecido em todas as Constituições de países democráticos: o da liberdade de expressão e de informação. A televisão de serviço público é considerada um dos meios de concretização desse direito constitucional 5 .

\section{O serviço público de TV: principios e valores}

A igualdade, a neutralidade, a continuidade e a mutabilidade são considerados os grandes princípios clássicos do serviço público. No entanto, em obediência à necessidade de adaptação, há quem avance «novos

4 Procurando explicar o modelo europeu de rádio e televisão - dentro do qual desenvolve o caso da BBC - Laurindo Lalo Leal Filho perspectiva-o a partir do poder que os media têm para se constituírem como veículos de produção cultural de uma nação. No entanto, reconhece ser ilícito desligar os elementos culturais dos factores técnicos e dos contextos políticos. Influenciando distintamente o modelo de serviço público, estes três elementos encontram-se, segundo Lalo Leal, intrinsecamente ligados, embora apresentem naturezas distintas.

5 No quadro do direito-garantia da liberdade de imprensa e dos meios de comunicação social, o Estado português, para além de consagrar constitucionalmente a liberdade de expressão e de informação, institui também a existência e o funcionamento de um serviço público de radiodifusão, que declara que lhe compete assegurar $\left[\operatorname{art}^{\circ} 38, \mathrm{n} .^{\circ} 5\right.$, Constituição $^{\circ}$ da República Portuguesa e art. 5. ${ }^{\circ}$ da Lei (da Televisão) n..$^{\circ}$ 31-A/98, de 14 de Julho]. 
princípios», nomeadamente os de transparência, de simplicidade e de participação (Pontier, 1996: 93-97). Para a temática que nos propomos abordar - o tratamento mediático da realidade regional — apenas iremos considerar os dois primeiros.

O princípio de igualdade é uma extensão do princípio jurídico que coloca todos os cidadãos ao mesmo nível perante a lei, impedindo qualquer espécie de discriminação ${ }^{6}$. Restringindo-nos ao trabalho dos jornalistas, este princípio tem uma aplicabilidade permanente, sendo a parcialidade ou a manipulação atitudes ética e juridicamente reprováveis. No entanto, nem sempre os meios de comunicação social dispõem de uma estrutura ou de uma política editorial que lhes permitam fazer chegar o seu produto/serviço jornalístico a todos os consumidores/cidadãos. Num serviço público de televisão, o princípio de igualdade alarga a possibilidade de recepção da mensagem audiovisual a todos os cidadãos que partilhem a nacionalidade do órgão público.

Proporcionar o acesso gratuito de todos às emissões televisivas implica, para além de uma cobertura integral do território, a criação de dispositivos que permitam, por exemplo, fazer chegar aquilo que se transmite através do som àqueles que não ouvem. Daqui resultam custos acrescidos que as empresas privadas nem sempre podem suportar, sob risco de verem afundar a rentabilidade dos seus projectos. O serviço público tem aqui responsabilidades acrescidas, embora nem sempre as cumpra. Em Portugal, por exemplo, a RTP tem vindo a difundir os principais acontecimentos sem qualquer tradução gestual 7 .

A igualdade pode também ser concebida em termos de oportunidade de participação nos canais de comunicação. Isto pressupõe uma atenção equitativa aos valores das maiorias e das minorias. A igualdade será tanto maior quanto maior for a diversidade das emissões. Da informação televisiva de um canal de serviço público espera-se a promoção quer dos valores das maiorias, quer dos valores das minorias; quer das realidades

6 A Constituição da República Portuguesa consagra, no artigo $13 .^{\circ}$, o Princípio da Igualdade, afirmando que todos "são iguais perante a lei» e que "ninguém pode ser privilegiado, beneficiado, prejudicado, privado de qualquer direito ou isento de qualquer dever em razão de ascendência, sexo, raça, língua, território de origem, religião, conviç̧ões políticas ou ideológicas, instrução, situação económica ou condição social».

7 Recorrendo ao artigo $37 .^{\circ}$ da Lei Fundamental, segundo o qual todos os cidadãos têm o direito de se informarem e serem informados sem impedimentos, o CDS-PP entregou na Assembleia da República, em Fevereiro de 1998, um projecto de resolução onde incentivava - Instituto da Comunicação Social a sensibilizar a RTP para a necessidade de tradução gestual da cobertura noticiosa dos principais acontecimentos nacionais e estrangeiros. 
urbanas, quer das realidades periféricas; quer das posições oficiais, quer das posições da vox populi.

O princípio de neutralidade manifesta-se como um princípio moral que orienta o serviço público na sua "actividade de prestação", impedindo qualquer juízo de valor (Isar, 1995: 314). Este princípio pressupõe que os serviços funcionem com vista a satisfazer apenas o interesse geral, não cedendo a interesses particulares. Neste ponto, restringimo-nos à perspectiva técnico-jurídica, excluindo a visão político-pragmática, a partir da qual este princípio exigiria outro tipo de reflexões.

É o princípio de neutralidade - e não o de igualdade - que preside ao reconhecimento do direito de acesso à antena por parte dos partidos políticos, do Governo, das organizações sindicais, profissionais e representativas das actividades económicas e das associações de defesa do ambiente e do consumidor - uma obrigação de que estão isentas as televisões privadas portuguesas ${ }^{8}$. Assegurar a concretização deste princípio foi, desde sempre, um dos grandes desafios do serviço público de televisão.

Certos autores consideram a neutralidade como uma exigência do princípio de igualdade. Todavia, como lembra Jean-François Lachaume (1989), o princípio de neutralidade diz respeito aos deveres que os serviços públicos têm para com os seus utilizadores, enquanto o princípio de igualdade tem subjacente os direitos dos utilizadores face aos serviços públicos. Aliado ao princípio de neutralidade está o de liberdade. Sem ela, os media não podem praticar aquilo que Denis McQuail (1994:142) apelida de «watchdog role», ou seja, não podem exercer vigilância pública relativamente àqueles que detêm mais poder na sociedade.

O princípio da neutralidade impõe um conjunto de deveres aos responsáveis pelos serviços públicos, sendo o mais importante deles a imparcialidade. Segundo Hervé Isar há duas formas de evitar a parcialidade:

- o pluralismo: abrir a emissão a diferentes grupos representativos de credos, pensamentos e políticas;

- o equilíbrio: não permitir a expressão de um único ponto de vista, ou seja, respeitar o «princípio do contraditório».

Este princípio não condiciona o funcionamento estrutural do serviço público, mas orienta o conteúdo dos programas. «A sua lógica profunda visa colocar o serviço prestado numa posição que impossibilite a promoção

8. Cf. artigo $49 .^{\circ}$ da Lei n. $31-\mathrm{A} / 98$, de 14 de Julho ( Lei da Televisão»). 
de um único ponto de vista sobre determinada realidade» (Isar, 1995: 313). A sua visibilidade traduz-se por normas que, para além de proibirem a discriminação, procuram uma certa objectividade. Mais do que os canais privados, aconselha-se o serviço público de televisão a desenvolver a sua actividade sem exclusões culturais ou sociais. À semelhança do Ėstado que o sustenta, ele deverá também ser independente e imparcial.

Jay Blumler e Wolfgang Hoffman-Riem (1992: 202) fazem coincidir os objectivos da televisão pública com os princípios que a norteiam. Só assim a actividade televisiva consegue desprender-se dos jugos normativos, erguendo uma programação alicerçada em valores específicos - que Blumler designa como "vulneráveis» ${ }^{9}$ - cuja apreensão se pretende que aconteça no interior da própria empresa por osmose e não pela força de qualquer legislação. Os princípios já os conhecemos, falta, porém, saber quais os valores que os estruturam.

Qualidade dos programas. Este valor é conceptualizado por Blumler e Hoffman-Riem (1992: 212) a partir da relação entre as características de um programa e um conjunto de critérios de avaliação, preterindo-se o destaque de elementos isolados a favor do sistema dentro do qual se pretende criar vários tipos de excelência aos quais os responsáveis por determinado programa devem aspirar. Sobreposta às leis do mercado, a qualidade liga-se intrinsecamente à essência do serviço público de televisão, do qual se espera um contributo importante para a inovação dos formatos televisivos, para a criatividade, para a capacidade de gerar debates de relevância social e para desenvolver a autenticidade e a riqueza expressivas dos conteúdos emitidos.

Tendo em conta a multiplicidade de canais que invade o ecrã de televisão, Dominique Wolton (1992: 148) encara a qualidade como algo de essencial a preservar, particularmente nos canais públicos, onde considera ser mais viável a adopção de medidas que contrariem o mercantilismo dos conteúdos e, consequentemente, as produções cada vez mais internacionalistas e, por isso, desligadas das realidades onde os canais operam. A ligação

9 Termo apresentado pelo académico britânico Jay Blumler (Television and the Public Interest, Sage Publications, London, 1992, pp. 22-41) para caracterizar os valores orientadores da televisão pública, contrapondo-os aos «valores económicos», considerados estruturantes da televisão privada. Para Blumler, os valores vulneráveis que merecem uma protecção institucionalizada, particularmente no seio da televisão pública, são os seguintes: a qualidade, a diversidade, a identidade cultural, o distanciamento face às fontes de financiamento, a integridade da comunicação cívica e o bem estar das crianças e adolescentes. Trataremos apenas dos três primeiros por serem aqueles que se direccionam mais directamente para a temática que nos propomos desenvolver. 
da qualidade à promoção dos valores culturais é, com efeito, reiteradamente retomada pelos teóricos que estudam a televisão de serviço público. Concentrando-se apenas na informação, Cebrián Herreros (s/d: 138) precisa aquilo que considera ser um jornalismo de qualidade:

"A informação de qualidade exige uma visão global e contextualizadora dos factos; o contraste de fontes e a depuração dos dados; o aprofundamento das consequências sociais, políticas e económicas; a busca de um equilibrio na cobertura territorial, social e cultural; o enfoque pluralista e imparcial das opiniões, propostas de soluções e críticas dos diversos grupos que convivem numa sociedade democrática. É necessária uma diversidade e especialização dos conteúdos informativos conforme os interesses dos múltiplos grupos que compõem a vida social.»

Os padrões de qualidade são indivisíveis, abrangem toda a grelha de programação, sendo, porém, conveniente estarem espelhados em cada programa. Daí serem inconsistentes as teses daqueles que defendem a distribuição do serviço público por vários canais 10 .

Diversidade. Uma programação diversificada nos planos regional, político e cultural é o que se espera dos operadores públicos. Emitindo para um conjunto de cidadãos com modos de vida diferenciados, a televisão de serviço público, mais do que as estações generalistas privadas, tem obrigação de reflectir nas suas emissões realidades multiformes, não apenas aquelas que chegam às maiorias, mas também aquelas que se restringem a grupos minoritários. Uma maior atenção à diversidade é também o alerta deixado por alguns sociólogos:

"Substituimos nas nossas sociedades hipercomplexas a ideia de que a eficácia está ligada à homogeneidade e à uniformidade pela ideia contrária de que esta está ligada à quantidade de informações criada ou mantida no sistema, isto é, à sua diversidade. Já não consideramos como um enriquecimento o abandono das culturas e das línguas locais, pelo contrário, parecenos cada vez mais que a riqueza de um conjunto é feita da sua diversidade e da sua flexibilidade» (Touraine, 1984/1996: 116).

Ao mesmo tempo que satisfaz os interesses dos membros individuais de uma audiência, uma grelha diversificada promove a coesão entre grupos que habitam espaços físicos distintos e que estruturam o seu quotidiano através de sistemas específicos. "Oferecer programas destinados a públicos diferentes é a melhor maneira de satisfazer o maior número de pessoas",

10 A respeito do conceito e da avaliação da qualidade em televisão, cf. Sakae Ishikav (ed.) - Quality Assessment of Television, John Libbey Media, 1996. 
garante, por sua vez, o relatório sobre o Futuro da Televisão Pública elaborado em França em 1994.

Wolfgang Hoffmann-Riem (1992: 49) distingue diferentes dimensões a partir da diversidade:

- uma diversidade orientada para o individuo ou grupo, proporcionando-lhes oportunidades de expressão;

- uma diversidade vocacionada para os temas;

- uma diversidade integradora de realidades de diferentes áreas territoriais;

- uma diversidade de formatos.

Identidade cultural. Conscientes de que as identidades colectivas atravessam um período de turbulência, os investigadores ligados ao estudo da televisão vêem nela um importante meio para consolidar a identidade cultural de um país. A fim de garantir a preservação deste valor, alguns países impuseram às estações de televisão, com incidência nos canais públicos, um reforço da língua nacional, serviços especiais para cada região e determinadas cotas de programas de produção nacional.

Quando se fala de cultura, devem ter-se em mente os vários tipos de manifestações que ela poderá assumir. Dominique Wolton (1997: 116), por exemplo, fala-nos de quatro tipos de culturas:

- a de elite;

- a de massa;

- a popular;

- a das minorias.

De todas elas a televisão dá-nos eco, apesar de prestar mais atenção à segunda. E é aqui que começam todos os problemas, pois a grande dificuldade passa a ser, por um lado, criar a diversidade numa cultura de massas - algo obrigatório para qualquer media generalista instalado num regime democrático - e, por outro, promover as manifestações inerentes a outras culturas - algo incontornável num canal televisivo de serviço público. Tendo como referência uma economia de televisão mista, Jay Blumler e Wolfgang Hoffman-Riem (1992: 211) reclamam para os operadores públicos a obrigação de se ocuparem das necessidades culturais mais autóctones. 


\section{O serviço público de TV: a informação regional no Telejornal}

Num texto retirado do seu livro Les territoires de la communication, e publicado no n. ${ }^{\circ} 57$ dos "Dossiers de l'Audiovisuel», Isabelle Pailliart opõe o local ao global, construindo a partir daqui uma série de oposições que culmina no confronto entre o local e o Estado. Do centro da sua tese emerge o sujeito, um retorno perspectivado a partir da crescente valorização da micro-sociedade cuja visibilidade só se torna possível graças aos media. Olivier Pasquet, num artigo publicado na mesma edição dos "Dossiers de l'Audiovisuel», reitera a importância da mediatização dos acontecimentos locais para a própria comunidade onde eles ocorrem. Na sua opinião, a visão catódica proporcionada pela televisão mistifica uma realidade até então olhada de forma anódina.

Concentrando-nos num canal de serviço público específico - a RTP1 iremos ver quais os acontecimentos regionais que mereceram destaque no seu programa de informação de maior audiência, o Telejornal. Os anos do estudo reportam-se, como já sublinhámos, a 1988 e a 1992. A nossa amostra foi constituída pelos alinhamentos semanais dos meses de Fevereiro, Maio, Agosto e Dezembro, considerando apenas os dias úteis. Em termos numéricos, o nosso corpus de análise foi de 171 noticiários (87 em 1988 e 84 em 1992), o que implicou a classificação de 3061 peças que totalizaram 90h 52m 01 ( $43 \mathrm{~h} \mathrm{46m} 50$ em 1988 e 47h 05m 11 em 1992). Para o estudo da realidade regional, optámos por classificar temática 11 e geograficamente 12 as peças nacionais.

Antes de apresentarmos os resultados da nossa análise, convém conhecer aquilo que os vários enquadramentos legais impunham, na época e no domínio da cobertura mediática da realidade regional, à televisão portuguesa de serviço público.

Na Lei 75/79, de 29 de Novembro, colocava-se como primeiro objectivo da radiotelevisão o de «contribuir para a formação $e$ informação do povo português, defendendo e promovendo os valores culturais do país, designadamente a língua portuguesa" (artigo 3..$^{\circ}$ ). Na Lei 58/90, de 7 de Setembro, reitera-se o mesmo propósito, fazendo-se alguns ajustamentos: substitui-se o «povo português» pelo "público» e relativizam-se os valores culturais, apontando-se apenas aqueles "que exprimem a identidade nacional». No entanto, insiste-se na defesa das raízes e da singularidade do público,

11 A tipologia criada para a classificação de todas as peças nacionais ascendeu a cerca de cinquenta categorias temáticas. Neste artigo apenas apresentámos aquelas que adquiriram visibilidade mediática a nível regional.

12 Para classificar as peças do ponto de vista geográfico recorremos a quatro categorias:

Lisboa, Porto, ilhas e resto do país. 
sublinhando-se a necessidade de atender à sua "diversidade em idades, ocupações, interesses e origens" (artigo 6. ${ }^{\circ}$ ). A nível estrutural, a RTP tentou responder a essa exigência de pluralidade imposta às suas emissões, multiplicando delegações e centros regionais por todo o território nacional. Três anos depois da sua primeira emissão e dois anos depois do início das suas emissões regulares, a estação pública inaugurava um Centro de Produção no Porto (1959). Em 1972 fazia o mesmo na Madeira e, três anos mais tarde, em 1975, inaugurava o dos Açores. Em 1988, instala delegações nas cidades de Vila Real, Viseu, Coimbra e Évora e procede à renovação do equipamento da delegação de Faro. Em 1992 é inaugurada uma nova delegação: em Bragança.

Vamos, então, ver que de que modo os princípios e valores do serviço público de TV, as normas jurídicas e a estrutura ramificada da RTP se espelham na mediatização dos acontecimentos que ocorrem fora da capital.

\subsection{O Porto}

A partir de 1987, o Centro de Produção do Porto começou a assegurar diariamente a emissão do período da manhã através de um programa de informação, o Bom Dia, e um de entretenimento, o Às Dez. Dois anos antes, em 1985, criara-se um programa diário de informação à hora do almoço: o Jornal da Tarde. Produzido em grande parte pela redacção do Monte da Virgem em Vila Nova de Gaia, este programa noticia assuntos nacionais e internacionais, mas concede primordial atenção a assuntos regionais, particularmente àqueles que têm lugar na zona do Grande Porto, como, aliás, ainda hoje acontece. No entanto, ao analisar os acontecimentos que, no período em estudo, se reportam a essa zona, forçoso será concluir que grande parte do trabalho matinal da redacção do Monte da Virgem não é aproveitada pelo Telejornal e, quando o é, as preferências concentram-se na actualidade dita nacional (acontecimentos ligados à diplomacia, ao Estado e aos partidos). Excluindo os acontecimentos espectaculares (acidentes, protestos e casos de polícia), a nossa amostra leva-nos a afirmar que muito pouco se ficou a conhecer do Porto.

Em 1988 apenas 4 das 16 categorias que integram acontecimentos que ocorreram no Porto ultrapassaram os 3 minutos, reportando-se duas delas a realidades puramente nacionais (Estado e partidos). Em 1992 nenhuma das 7 categorias que relatam factos da região portuense conseguiu ir além dos 3 minutos. Ao contrário daquilo que aconteceu com o resto do país, o Porto perdeu espaço no noticiário em 1992. Em 1988, a cidade invicta ocupou 1 h $02 \mathrm{~m} 30$ de emissão, ou seja, 2,37\% do tempo global do noticiário. Quatro anos mais tarde, apenas consegue $07 \mathrm{~m} 35$, o que equivale a uma percentagem de $0,26 \%$. 
QUADRO 1: CATEGORIAS NO TELEJORNAL REFERENTES AO PORTO

\begin{tabular}{|c|c|c|c|}
\hline \multicolumn{2}{|c|}{1988} & \multicolumn{2}{c|}{1992} \\
\hline CATEGORIAS & $\begin{array}{c}\text { TEMPO } \\
\text { Por segundos }\end{array}$ & CATEGORIAS & $\begin{array}{c}\text { TEMPO } \\
\text { Por segundos }\end{array}$ \\
\hline Acidentes & 100 & Artes & 33 \\
\hline Artes & 100 & Casos de Polícia & 89 \\
\hline Autarquias & 333 & Economia & 111 \\
\hline Construções & 107 & Educação & 125 \\
\hline Diplomacia & 108 & Estado & 38 \\
\hline Economia & 531 & Partidos & 37 \\
\hline Educação & 111 & Vida Quotidiana & 22 \\
\hline Emigração & 99 & - & \\
\hline Estado & 441 & - & \\
\hline Língua - Livros - Escritores & 78 & - & \\
\hline Mortes & 82 & - & \\
\hline Partidos & 1167 & - & \\
\hline Protestos & 107 & - & \\
\hline RTP & 115 & - & \\
\hline Saúde & 107 & - & \\
\hline Sindicatos - Associações & 73 & - & \\
\hline
\end{tabular}

\subsection{As Ithas}

Os estúdios da RTP nas ilhas são inaugurados na primeira metade dos anos 70. No entanto, há que esperar pela entrada da década de 80 para que essas delegações, entretanto convertidas em Centros Regionais, conquistem autonomia financeira e de gestão que lhes permitisse, para além de transmitir em directo ou em diferido os programas da RTP, organizar e elaborar a sua própria emissão. Este tipo de competências foi fixado pelo Decreto-Lei n. ${ }^{\circ}$ 156/80, de 24 de Maio. A partir daí, os Centros Regionais dos Arquipélagos estavam autorizados a produzir programas próprios. No continente, esse trabalho, pelo menos ao nível da informação, manteve-se, no período em estudo, praticamente silenciado.

Em 1988, os arquipélagos ainda conseguiram marcar presença para lá dos assuntos que são sempre notícia independentemente do lugar onde ocorrem, como acontece com os acidentes, o automobilismo, os casos de policia, os partidos e o Estado. Nesse ano conheceram-se alguns problemas sociais do povo das ilhas, descobriram-se falhas no sistema de saúde, falou-se da economia dos arquipélagos e sentiu-se o pulsar do poder das autarquias. Em 1992, e tal como aconteceu com o Porto, dedicou-se 
menos atenção às ilhas. Os casos de polícia e os assuntos diplomáticos e de Estado continuaram a ser notícia, mas, para além deles, apenas houve um breve espaço para dois temas - o ambiente e os problemas sociais que totalizaram $4 \mathrm{~m} 56$.

Em termos quantitativos, o Telejornal forneceu-nos, nos quatro meses estudados em 1988, 22m 48 de notícias sobre as ilhas da Madeira e dos Açores, o que, em termos percentuais, se traduz em 0,86\%. Em 1992 as notícias dos arquipélagos restringiram-se a $19 \mathrm{~m} 24$, o que significa uma percentagem de $0,68 \%$.

QUADRO 2: CATEGORIAS NO TELEJORNAL REFERENTES ÀS ILHAS

\begin{tabular}{|c|c|c|c|}
\hline \multicolumn{2}{|c|}{1988} & \multicolumn{2}{|c|}{1992} \\
\hline CATEGORIAS & $\begin{array}{c}\text { TEMPO } \\
\text { Por segundos }\end{array}$ & CATEGORIAS & $\begin{array}{c}\text { TEMPO } \\
\text { Por segundos }\end{array}$ \\
\hline Acidentes & 123 & Ambiente & 18 \\
\hline Autarquias & 191 & Casos de Polícia & 128 \\
\hline Automobilismo & 139 & Diplomacia & 149 \\
\hline Casos de Polícia & 33 & Estado & 517 \\
\hline Economia & 215 & Problemas Sociais & 278 \\
\hline Estado & 365 & - & \\
\hline Partidos & 66 & - & \\
\hline Problemas Sociais & 42 & $=$ & \\
\hline Saúde & 67 & - & \\
\hline
\end{tabular}

\subsection{O resto do país}

Os valores obtidos no estudo do Telejornal, emitido durante os meses de Fevereiro, Maio, Agosto e Dezembro de 1988 e de 1992, não permitem dizer que a RTP faz, no seu principal programa de informação, uma cobertura equilibrada daquilo que acontece no país.

Nos quatro meses estudados em 1988, o Telejornal manteve-se no ar $43 \mathrm{~h}$ $46 \mathrm{~m}$ 50, mas o resto do país (donde excluímos Lisboa, Porto e ilhas) conseguiu apenas $2 \mathrm{~h} 08 \mathrm{~m} 10$, o que equivale a um resultado de $4,87 \%$. Em 1992, se bem que as notícias de âmbito nacional tenham sofrido um decréscimo considerável, a informação dita regional conquistou mais espaço. Das 47h 22m 12 de emissão, o Telejornal dedicou ao resto do país $4 \mathrm{~h} 22 \mathrm{~m} 12$, ou seja, $9,28 \%$ do tempo global.

Destacar assuntos puramente regionais que são notícia apenas em determinado espaço não constituiu uma prioridade em 1988. Nove das 19 categorias onde se integram os acontecimentos que ocorreram fora do 
Porto e de Lisboa chegaram, nesse ano, ao Telejomal ou porque diziam respeito a factos que foram deslocados da capital para a província (Estado, assuntos militares e internacional-religião) ou porque davam conta de acontecimentos que colidiam com a normalidade imposta ao tecido social (mortes, trânsito, casos de polícia, julgamentos, acidentes e protestos). Os outros acontecimentos integram-se em 10 categorias, 6 das quais reunindo um tempo inferior a $06 \mathrm{~m}$ (património, vida social, ambiente, educação, artes e sindicatos) e as restantes não ultrapassando os $17 \mathrm{~m}$ (autarquias, construções, festividades e economia).

QUADRO 3: CATEGORIAS NO TELEJORNAL REFERENTES AO RESTO DO PAIS

\begin{tabular}{|c|c|c|c|}
\hline \multicolumn{2}{|l|}{1988} & \multicolumn{2}{|l|}{1992} \\
\hline CATEGORIAS & $\begin{array}{c}\text { TEMPO } \\
\text { Por segundos }\end{array}$ & CATEGORIAS & $\begin{array}{c}\text { TEMPO } \\
\text { Por segundos }\end{array}$ \\
\hline Acidentes & 1466 & Acidentes & 3137 \\
\hline Ambiente & 306 & Ambiente & 1396 \\
\hline Artes & 320 & Artes & 124 \\
\hline Assuntos Militares & 158 & Assuntos Militares & 152 \\
\hline Autarquias & 397 & Autarquias & 384 \\
\hline Casos de Polícia & 178 & Casos de Polícia & 475 \\
\hline Construções & 390 & Casos Pessoais & 758 \\
\hline Economia & 988 & Construções & 502 \\
\hline Educação & 333 & Curiosidades & 140 \\
\hline Estado & 710 & Economia & 756 \\
\hline Festividades & 585 & Educação & 287 \\
\hline Internacional - Religião & 83 & Emigração & 254 \\
\hline Julgamentos & 81 & Estado & 374 \\
\hline Mortes & 84 & Festividades & 427 \\
\hline Património - História & 160 & Intern.- Espectáculos & 255 \\
\hline Protestos & 440 & Intern. - Política & 262 \\
\hline Sindicatos - Associações & 213 & Intern.- Problemas Sociais & 191 \\
\hline Trânsito & 312 & Julgamentos & 1352 \\
\hline Vida Social & 113 & Partidos & 682 \\
\hline- & & Património - História & 341 \\
\hline- & & Problemas Sociais & 308 \\
\hline- & & Protestos & 1103 \\
\hline - & & Religião & 123 \\
\hline- & & Saúde & 264 \\
\hline- & & Sindicatos & 196 \\
\hline - & & Timor & 126 \\
\hline - & - & Trânsito & 98 \\
\hline - & & Vida Quotidiana & 898 \\
\hline - & & Vida Social & 102 \\
\hline
\end{tabular}


Em 1992, as regiões continuaram a ser notícia, ora porque houve uma deslocação de fontes que fazem habitualmente notícia de Lisboa para determinada região (Timor, assuntos militares, Estado e partidos), ora porque irrompeu da realidade quotidiana uma situação anómala (protestos, casos de polícia, acidentes e julgamentos). No entanto, como se alargou o espaço para o resto do país, houve mais tempo para se noticiarem factos que se enraizavam no dia-a-dia de determinada população. Nesse ano, mostraram-se artes locais, descobriram-se curiosidades, exibiu-se a vida social de determinados grupos, apontaram-se lacunas na educação, exibiu-se património regional, denunciaram-se problemas sociais, sublinharam-se falhas no sistema de saúde, descobriram-se festividades, ampliaram-se atentados contra o ambiente, retrataram-se casos pessoais, falou-se da micro-economia e desvendaram-se algumas facetas da vida quotidiana. Em suma: alargou-se o espaço para noticiar o que pertence, de facto, a cada região. Todavia, em termos de tempo, a atenção dada ao resto do país foi ainda muito reduzida, como, aliás, os números do Quadro 3 comprovam.

\subsection{E o serviço público?}

Um dos princípios que orientam a actividade de um canal público de televisão é o da igualdade, que se assume como uma extensão do princípio jurídico que defende a atribuição dos mesmos direitos a todos os cidadãos e pressupõe uma preocupação permanente não só com os valores das maiorias, mas também com o património das minorias, daqueles que permanecem à margem, porque estão fisicamente longe dos centros ou culturalmente distantes dos padrões socialmente estabelecidos.

No período em análise, verificámos um constante esquecimento daquilo que se passa fora de Lisboa, como, aliás, se pode constatar no gráfico 1. Se a função informativa da televisão de serviço público se cumpre na mediação de diferentes universos, através do Telejornal aquilo que se tornou comum foi predominantemente uma realidade de uma elite, a do poder. Do principal programa de informação da RTP os portugueses não receberam - como seria de esperar - um melhor e mais abrangente conhecimento da diversidade do património nacional. Faltou-lhe uma política de abertura às diversas tendências da sociedade, às culturas regionais e às novas formas de expressão.

Pelo estudo das categorias em que se integram os acontecimentos regionais do periodo que estudámos, constata-se que a diversidade e a identidade cultural, valores intrínsecos a um serviço público de televisão, primam pela ausência. E a cobertura abrangente, um dos motivos invocados para o fortalecimento do serviço público na Europa, apenas se torna visível 

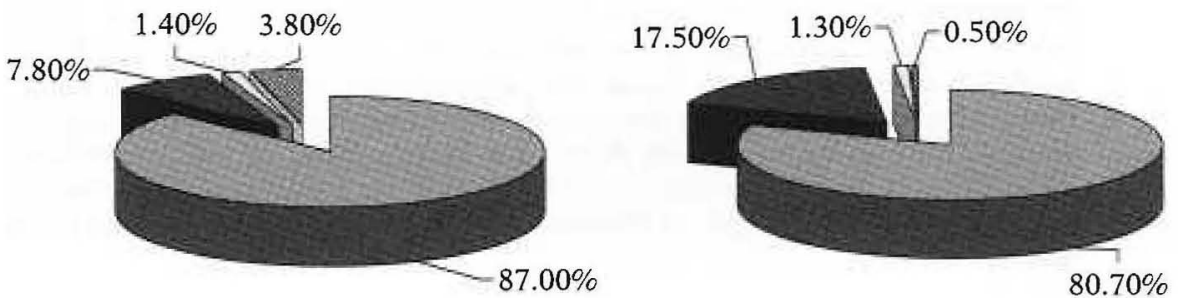

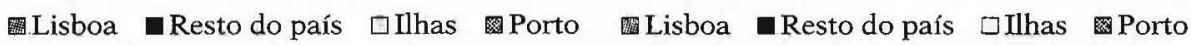

GRÁFICO 1: INFORMAÇĀO NACIONAL NO TELEJORNAL EM 1988 E EM 1992

quando se estuda a mancha geográfica que recebe as emissões da RTP. Se quisermos tomá-la como referência na análise de conteúdo das peças dos alinhamentos do Telejornal, verificamos que a realidade nacional mediatizada se circunscreve, na sua maior parte, à área de Lisboa, como é demonstrado no gráfico 1.

A fraca representatividade de acontecimentos regionais, para além de ser um facto no principal bloco diário de informação da televisão de serviço público, estende-se também à grelha de programação da RTP 1, referente a 1988 e a 1992, onde não se encontra qualquer programa de informação de índole regional.

\section{Notas finais}

Sendo indiscutível a capacidade do pequeno écrã para se assumir como promotor de acontecimentos, poder-se-á também falar da sua força para fortalecer a coesão social. No entanto, esse poder apenas é exercido com alguma extensão se os factos noticiados forem diversificados quer temática quer geograficamente.

Uma informação pluralista (nos temas, nas fontes e nos territórios mediatizados) contribui decididamente para a aproximação de gentes com diferentes modos de vida. Dominique Wolton (1997: 105), acérrimo defensor dos canais generalistas, sustenta que este modo de encarar a televisão é o único capaz de proporcionar uma comunicação congregadora de diferentes grupos sociais. É por aqui que passa também o futuro da televisão de serviço público.

«A televisão»- segundo este sociólogo - «assemelha-se à meteorologia. Em primeiro lugar, interessam-nos as previsões para a nossa região, assim como nos interessam certos programas em detrimento de outros. 
No entanto, estamos conscientes de que a meteorologia para a nossa região não se traça de forma autónoma, não podendo, por isso, ser isolada de um contexto mais abrangente, ainda que acreditemos estar num microclima. Para além disso, gostamos sempre de estar informados sobre o que se passa lá fora, porque cada um de nós tem sempre noutros sítios familiares ou amigos. Acrescente-se que o nosso entendimento das previsões meteorológicas sobre um lugar é proporcional ao conhecimento espacial que dele temos."

Wolton serve-se desta metáfora para legitimar a força dos canais generalistas. Com ela, pretendemos manter-nos numa realidade específica: a cobertura mediática dos acontecimentos regionais. Transpostas as afirmações do sociólogo francês para um alinhamento de um telejornal, defenderse-á uma informação diversificada, integradora de diferentes realidades. Legitimam-se, entre outras coisas, a difusão de informação internacional, nacional e regional; a coabitação das fontes oficiais com as não oficiais; a selecção de factos que interessam às massas paralelamente a outros que apenas suscitam interesse numa minoria.

Os registos da nossa amostra fazem-nos pensar num Telejornal como espaço de reprodução de realidades predominantemente urbanas. Restringindo-nos ao período em estudo, pode afirmar-se que a RTP se revelou, ao longo desse tempo, algo adversa ao localismo e aos aspectos idiossincráticos dos cidadãos que habitam fora de Lisboa. As (baixas) percentagens reunidas pelos acontecimentos nacionais que ocorreram fora da capital demonstram que o principal noticiário da televisão de serviço público, apesar de ser para todos os portugueses, era concebido por um grupo circunscrito à capital do país. 


\section{BIBLIOGRAFIA}

Amaral, Diogo Freitas do (1989), Curso de Direito Administrativo, Livraria Almedina, Coimbra, Vol. I.

Blumler, Jay G. (ed), (1992), Television and the Public Interest, Sage Publications, London.

Blumler, Jay e Hoffman-RIEm, Wolfgang (1992), "New Roles for Public Service Television» in Jay Blumler (ed), Television and the Public Interest, Sage Publications, London.

BouRdieu, Pierre (1997), Sobre a Televisão, Celta Editora. (Trabalho original em francês, s/d.)

CAYrol, Roland (1991), Lés Médias: presse écrite, radio, télévision, Presses Universitaires de France.

Cebrián Herreros, Mariano (s/d), Información televisiva. Mediaciones, contenidos, expresión y programación, Ed. Sintesis, Madrid.

HofFMAN-RIEM, Wolfgang (1992), "Protecting Vulnerable Values in the German Broadcasting Order» in Jay Blumler (ed), Television and the Public Interest, Sage Publications, London.

IsAR, Hervé (1995), Le Service Public et la Communication Audiovisuelle, Presses Universitaires d'Aix-Marseille, Collection Droit de l'Audiovisuel.

IsHIKAV, Sakae (1996), Quality Assessment of Television, John Libbey Media.

Lachaume, Jean-François (1989), Grands Services Publics, Masson, Paris.

LEAL, Laurindo Lalo (1997), A Melhor TV do Mundo: o Modelo Britânico de Televisão, Summus Editorial, São Paulo.

McQuall, Denis (1994), Mass Communication Theory - an introduction, Sage Publications, Thrid Edition, London.

RICHERI, Giuseppe (1994), La Transición di la televisión-análisis del audiovisual como empresa de comunicación, Col. Bosch Comunicación, Barcelona. (Trabalho original em italiano publicado em 1993.)

SARTORI, Giovanni (1998), Homo Videns - La sociedad teledirigida, Taurus, Madrid. (Trabalho original em italiano publicado em 1993.)

Touraine, Alain (1996), O Retorno do Actor - ensaio sobre sociologia, Instituto Piaget, Col. Economia e Política. (Trabalho original em francês publicado em 1984.)

Wolton, Dominique (1992), "Values and Normative Choices in French Television» in Jay Blumler (ed), Television and the Public Interest, Sage Publications, London.

Wolton, Dominique (1997), Penser la Communication, Flammarion.

\section{Relatórios}

Anuário da RTP de 1988, Direcção dos Arquivos Audiovisuais e Documentação, Subdepartamento de Registo e Estatística de Emissões da RTP.

Anuário da RTP de 1992, Departamento de Arquivos e Documentaçāo, Serviço de Verificação e Estatística, Centro de Documentação da RTP.

(1994), L'avenir de la télévision publique, Collection des Rapports Officiels, La Documentation Française, Paris. 


\section{Revistas}

Dossiers de l'Audiovisuel, n. 57 - «La TV de proximité», Septembre/Octobre 1994, INA (Institut National de l'Audiovisuel):

\section{Legislação}

Lei 75/79-I Série, n. ${ }^{\circ} 276$, de 29 de Novembro.

Lei 58/90-I Série, n. ${ }^{\circ} 207$, de 7 de Setembro.

Lei 31- A/98- I Série, de 14 de Julho.

Revisão do Contrato de Concessão de Serviço Público, 31 de Dezembro de 1996. 